\title{
Resistência térmica de células vegetativas de Clostridium perfringens em patê de fígado com nozes e passas
}

Everton Conceição da Silveira

Eliane Maria Manara Rossoni

Fernanda Marques Souza Godinho
Fundação de Ciência e Tecnologia - CIENTEC, Departamento de Alimentos, Laboratório de Microbiologia, Porto Alegre, RS. Brasil.

E-mail: silveira.ec@gmail.com

emmrossoni@gmail.com

fernandamsg@yahoo.com.br

Recebido em: 25 fevereiro 2018. Aceito em: 1 junho 2018.

DOI: http://dx.doi.org/10.21674/2448-0479.43.501-511

\section{Resumo}

Células vegetativas de Clostridium perfringens ATCC 13124 inoculadas em patê de fígado foram submetidas a diferentes tratamentos térmicos para caracterização de sua resistência ao calor e evidenciar a eficiência de modelo preditivo na obtenção de tempos de tratamento térmico. Frações experimentais de aproximadamente $8,50 \mathrm{~g}$ de amostras foram inoculadas e examinadas para obtenção de valores Dobservados, construção de modelo preditivo, no intervalo térmico de $56,7^{\circ} \mathrm{C}$ a $66,3^{\circ} \mathrm{C}$, e, posteriormente, evidenciar a eficiência do modelo através da enumeração de células sobreviventes na temperatura de $67,5^{\circ} \mathrm{C}$ e verificação da linearidade em cotejos de valores $D$ ( $D_{\text {observados }}$ e $D_{\text {calculados }}$ ) em faixa térmica entre $56,7^{\circ} \mathrm{C}$ e $67,5^{\circ} \mathrm{C}$. A semelhança dos valores $D_{\text {observado }} \mathrm{e}$ $D_{\text {calculado }}(3,14 \mathrm{~min} \approx 2,94 \mathrm{~min})$ constatada no tratamento $2 \mathrm{D}_{67,5^{\circ} \mathrm{C}}$, a ausência de células sobreviventes nos tratamentos $8 \mathrm{D}_{67,5^{\circ} \mathrm{C}}$ e $12 \mathrm{D}_{67,5^{\circ} \mathrm{C}}$, juntamente com a marcada linearidade $(r=0,9934)$ da regressão entre os valores $D_{\text {observados }}(\sim 3,1-16,6 \mathrm{~min})$ e $D_{\text {calculados }}(\sim 2,9-15,6 \mathrm{~min})$ caracterizaram a eficiência do modelo preditivo no caso estudado.

Palavras-chave: Conservação alimentar. Tratamento térmico. Valor D. Modelo preditivo. Modelo preditivo.

\section{Abstract \\ Thermal resistance of vegetative cells of Clostridium perfringens in liver pate with nuts and raisins}


Vegetative cells of Clostridium perfringens ATCC 13124 inoculated in liver pates were submittes to different thermal treatments to characterize their heat resistance and demonstrate the efficiency of predictive model of in obtaining heat treatment times. Fractions of about $8.50 \mathrm{~g}$ experimental samples were inoculated and examined to obtain Dobserved values, predictive model construction in the temperature range of $56.7^{\circ} \mathrm{C}$ to $66.3^{\circ} \mathrm{C}$, and then evidence the model efficiency by cell enumeration survivors at the temperature of $67.5^{\circ} \mathrm{C}$ and verification of the linearity in comparisons of $D$ values ( $D_{\text {observed }}$ and $D_{\text {calculated }}$ ) in thermal range between $56.7^{\circ} \mathrm{C}$ and $67.5^{\circ} \mathrm{C}$. The similarity of $D_{\text {observed }}$ and $D_{\text {calculated values }}\left(3.14 \mathrm{~min} \approx 2.94 \mathrm{~min}\right.$ ) found in the $2 \mathrm{D}_{67.5^{\circ} \mathrm{C}}$ treatment, the absence of surviving cells in the $8 \mathrm{D}_{67.5^{\circ} \mathrm{C}}$ and $12 \mathrm{D}_{67.5^{\circ} \mathrm{C}}$ and treatments along with the labeled linearity $(r=0.9934)$ of the regression between $D_{\text {observed }}(\sim 3.1-16.6 \mathrm{~min})$ and $\mathrm{D}_{\text {calculated }}(\sim 2.9-15.6 \mathrm{~min})$ values characterized the efficiency of the predictive model in the case studied.

Keywords: Food preservation. Thermic treatment. D Value. Predictive model.

\section{Introdução}

Clostridium perfringens é uma bactéria mesófila capaz de desenvolver-se em uma amplitude térmica entre $12^{\circ} \mathrm{C}$ e aproximadamente 50ㄷ (LABBE; JUNEJA, 2002; MCCLANE, 2007; SILVA et al., 2010). Entretanto, de acordo com Juneja et al. (2010), seus exemplares possuem um ótimo térmico de crescimento que varia de 43 a $45^{\circ} \mathrm{C}$. São encontrados em diversos tipos de ambientes-fontes incluindo, entre outros, solo, poeira, água e trato intestinal de animais e humanos (JUNEJA et al., 2010; SILVA et al., 2010) contaminando alimentos crus e processados, especialmente carnes, ainda durante o processo de abate, e produtos cárneos em manipulações de produção (JAY, 2005; GOMES et al., 2008; JUNEJA et al., 2009; JUNEJA et al., 2010; LABBE, 2015).

Alguns tipos de células vegetativas de Clostridium perfringens (tipo A), quando colocadas em condições ambientais favoráveis ou de estresse, ainda dentro do intestino do hospedeiro, são produtoras de esporos e enterotoxinas potencialmente causadoras de intoxicações e doenças alimentares (FORSYTHE, 2002; JUNEJA et al., 2010; SILVA et al., 2010).

Sob condições ótimas de crescimento microbiano, segundo Labbe e Juneja (2002) e Juneja et al. (2010), doenças alimentares podem ocorrer quando o número de células vegetativas patogênicas de Clostridium perfringens em carnes e produtos cárneos é maior que $10^{6}$, podendo ainda causar dano equivalente, de acordo com Barretto (2000), em imunodeprimidos, transplantados, gestantes, crianças e idosos mesmo que expostos a doses infectantes menores que $10^{6} \mathrm{cel} . / \mathrm{g}$.

Sobrevivência e crescimento dos microrganismos, de acordo com Sinell (1980) e Forsythe (2002), regulam-se segundo características específicas e condições ambientais de exposição. Fatores intrínsecos e extrínsecos atuantes neste sistema interativo, de acordo com o caso, podem ser utilizados dentro de estratégias de conservação de produtos alimentares para estabelecer condições desfavoráveis que almejam a inativação bacteriana (FORSYTHE, 2002). 
Modelos matemáticos tornam-se ferramentas importantes para produção alimentar segura uma vez que caracterizam o comportamento bacteriano em diversas condições ambientais permitindo seu uso preditivo em estratégias de controle microbiológico sob condições conhecida para conservação alimentar (FORSYTHE, 2002; MCMEEKIN, et al. 2002; MILLER et al., 2004; JUNEJA et al., 2009).

Segundo Forsythe (2002) e McMeekin et al. (2002), tratamento térmico é um método universal milenário capaz de reduzir populações de bactérias deteriorantes e/ou patogênicas e, consequentemente, prolongar a vida de prateleira dos alimentos. Sabe-se que tais reduções, oriundas de tratamentos para conservação alimentar, variam de acordo com inúmeros fatores (e. g., intensidade do tratamento e resistência térmica das bactérias). No caso do Clostridium perfringens, sua resistência térmica afeta-se, também, pelas diferenças entre cepas e sua heterogeneidade, composição do diluente de aquecimento, conservantes adicionados, $\mathrm{pH}$ da amostra, tipo de matriz, exposição prévia ao estresse de calor e desenho experimental (OLSON; NOTTINGHAM, 1980; HEREDIA et al., 1997; JUNEJA et al., 2001; FORSYTHE, 2002; NOVAK; YUAN, 2004; HUANG et al., 2007; WIJNANDS et al., 2009; JUNEJA et al., 2010).

O presente trabalho tem por objetivo caracterizar a resistência térmica de células vegetativas de Clostridium perfringens ATCC 13124 em patê de fígado com nozes e passas e evidenciar a eficiência do modelo preditivo, apresentado por Jackson (2015), utilizado para obtenção dos tempos de tratamento térmico neste caso avaliado.

\section{Material e Métodos}

Os experimentos foram realizados no Laboratório de microbiologia do Departamento de alimentos da Fundação de Ciência e Tecnologia (CIENTEC) do Estado do Rio Grande do Sul no período compreendido entre maio e junho de 2017.

Das amostras de patê de fígado com nozes e passas fornecidas pelo produtor artesanal Newton Lauria para controle de qualidade e determinação da validade pós processamento, parte foram aproveitadas para realização das determinações dos experimentos.

\section{Culturas bacterianas}

A cultura do Clostridium perfringens ATCC 13124 utilizada nos experimentos foi adquirida da Microbiologics (catálogo oㅡ 0318CRM, lote ํㅜ 318-122) e preservada no Laboratório de microbiologia da CIENTEC a aproximadamente $-80^{\circ} \mathrm{C}$ em ultrafreezer (Thermo Scientific - 900 series) após ressuspensão.

As suspensões microbianas para contaminação das amostras de patê foram obtidas adicionando assepticamente $0,4 \mathrm{~mL}$ de cepa de trabalho (cultivo de $4^{\text {a }}$ passagem mantido a temperatura ambiente em caldo tioglicolato) a $4,0 \mathrm{~mL}$ de água peptonada tamponada.

\section{Inoculação de amostras}


As amostras de patê com nozes e passas foram mantidas sob refrigeração, entre $2^{\circ} \mathrm{C}$ e $6^{\circ} \mathrm{C}$, em sua embalagem original até a realização dos experimentos.

Dezesseis frações de $8,50 \mathrm{~g}$ de patês foram pesadas e transferidas assepticamente para quatro sacos de polietileno esterilizados $(13 \times 19 \mathrm{~cm})$ e 12 frascos de vidro com tampa $(2 \times 4 \mathrm{~cm})$.

Alíquotas de $1,0 \mathrm{~mL}$ de suspensão microbiana isentas de esporos foram adicionadas em cada fração de amostra elaborada onde posteriormente seguiu-se com a homogeneização e repouso, por cerca de $45 \mathrm{~min}$, de todos estes preparados para ambientação.

\section{Inativação térmica e enumeração bacteriana}

Os experimentos, conduzidos com temperatura controlada, foram desenvolvidos com auxílio de um equipamento de banho-maria provido de sistema de circulação de água (Marconi - MA 159) e de um sistema de aquisição e monitoramento da temperatura (Novus - Fieldlogger).

As 16 frações experimentais foram divididas em dois grupos. O primeiro, composto por três sacos mais nove frascos, forneceu dados para obtenção dos parâmetros de caracterização da resistência térmica e para elaboração do modelo preditivo e, o segundo grupo, composto por um saco mais três frascos, subsidiou a avaliação da eficiência do modelo preditivo utilizado.

Todos os sacos preparados não foram submetidos a tratamento térmico; foram utilizados para controle das temperaturas investigadas. Os nove frascos do primeiro grupo foram submetidos a temperaturas de $55^{\circ} \mathrm{C}$ e $60^{\circ} \mathrm{C}$ por 4,10 e 16 minutos e à temperatura de $65^{\circ} \mathrm{C}$ por 3,6 e 9 minutos. Os três frascos do segundo grupo foram submetidos a tratamentos térmicos baseados em múltiplos do tempo de redução decimal a $67,5^{\circ} \mathrm{C}$ (i. e., $2 \mathrm{D}_{67,5^{\circ} \mathrm{C},} 8 \mathrm{D}_{67,5^{\circ} \mathrm{C}}$ e $12 \mathrm{D}_{67,5^{\circ} \mathrm{C}}$ ). Todos os frascos preparados, depois de transcorridos os tempos de tratamentos, foram submetidos a resfriamento em água fria até o início dos procedimentos para contagem das células sobreviventes.

Para enumeração das células vegetativas sobreviventes transferiram-se para sacos esterilizados individuais todas as amostras preparadas em frascos e submetidas aos tratamentos térmicos do estudo. As enumerações foram feitas em todas as 16 frações preparadas (12 com tratamento térmico e 4 controles), por meio da: (1) recuperação de células sobreviventes em água peptonada tamponada diluente na proporção 1:9 (uma parte de amostra por nove partes de diluente); (2) inoculação de $1 \mathrm{~mL}$ de suspensão inicial em placas com aproximadamente $15 \mathrm{~mL}$ de Agar TSC sem cicloserina (com sobrecamada); (3) incubação em atmosfera anaeróbica por 48 horas a $37 \pm$ 1ํㅡ. Demais diluições seriadas foram realizadas também fazendo uso de água peptonada tamponada na referida proporção.

\section{Análise dos dados}

Para análise, tabulação e sistematização dos dados obtidos fez-se uso do programa Microsoft Excel 2007. Todos os experimentos foram realizados em uniplicada com diluições até $10^{-3}$.

Para o estabelecimento da curva de destruição térmica e obtenção do tempo de redução decimal (valor $D_{\text {observado) }}$ de cada temperatura investigada, os dados resultantes das enumerações dos tratamentos foram transformados em $\log _{10}$ UFC/g e plotados no eixo das ordenadas juntamente com 
os tempos transcorridos de cada experimento que foram colocados no eixo das abscissas em minutos.

O incremento de temperatura necessário para promover uma redução de $90 \%$ do valor $D$ (valor Z) foi obtido da curva de resistência térmica de acordo com equação apresentada por Jackson (2015) onde plota-se os valores do tempo de redução decimal no eixo das ordenadas em Log 10 min contra as respectivas temperaturas investigadas no eixo das abscissas em ${ }^{\circ} \mathrm{C}$.

Demais valores $D$ (valores $D_{\text {calculados }}$ ), relativos às temperaturas investigadas neste trabalho $e$ outras, foram obtidos segundo modelo preditivo apresentado por Jackson (2015).

Parâmetros descritivos do ajuste da regressão, tais como: coeficiente de determinação $\left(R^{2}\right)$ e coeficiente de correlação de Pearson (r), foram obtidos de acordo com Gotelli e Ellison (2011).

\section{Resultados e Discussão}

Considerando os tratamentos térmicos investigados experimentalmente do primeiro grupo de frações, conforme tabela 1, obtiveram-se variações do tempo de redução decimal entre, aproximadamente, 3,8 e 16,6min. Tendências acercadas para determinados tratamentos térmicos investigados neste trabalho foram comumente encontradas por outros autores em averiguações, porém utilizando condições experimentais diferentes. Juneja e Marmer (1998) avaliando dois substratos (matrizes) entre a faixa térmica de 55 a $62,5^{\circ} \mathrm{C}$ obtiveram valores $D$ de 1,6 a 21,7 min e de 1,3 a 17,6min. Sarker et al. (2000), Raju e Sarker (2005), encontraram, respectivamente, valores $D_{55^{\circ} \mathrm{C}}$ de 5,0 a 16,5min e 6,0 a 14,0min. Byrne et al. (2006) avaliando as temperaturas de 55, 60 e $65^{\circ} \mathrm{C}$, respectivamente obtiveram $16,3,8,5$ e $0,8 \mathrm{~min}$. Diferenças maiores são encontradas no trabalho de Heredia et al. (1997) que, examinando duas cepas, encontraram valores $D_{55^{\circ} \mathrm{C}}$ entre 4,5 e 9,6min (controle) e 9,0 e 86,0min (após choque térmico). Discordâncias, obtidas nas determinações do valor $D$, são explicadas a partir dos fatores anteriormente mencionados e outrora evidenciados por pesquisadores e. g., estudos entre cepas diferentes de Heredia et al., (1997), Raju e Sarker, (2005), Wijnands et al., (2009) que afetam a resistência térmica dos microrganismos.

Tabela 1 - Tratamentos e parâmetros de destruição e resistência térmica de células vegetativas do Clostridium perfringens em patê de fígado com nozes e passas.

\begin{tabular}{|c|c|c|c|c|c|}
\hline \multicolumn{2}{|c|}{ Tratamentos térmicos } & \multicolumn{2}{|c|}{$\begin{array}{c}\text { Curvas de destruição } \\
\text { térmica }\end{array}$} & \multicolumn{2}{|c|}{$\begin{array}{c}\text { Curva de resistência } \\
\text { térmica }\end{array}$} \\
\hline $\begin{array}{l}\text { Temperatura } \\
\text { alvo }\left({ }^{\circ} \mathrm{C}\right)\end{array}$ & $\begin{array}{l}\text { Temperatura } \\
\text { corrigida } \\
\left({ }^{\circ} \mathrm{C}\right)\end{array}$ & $\begin{array}{l}\text { Valor D } \\
\text { (min) }\end{array}$ & $\mathbf{R}^{2}$ & $\begin{array}{l}\text { Valor Z } \\
\quad\left({ }^{\circ} \mathrm{C}\right)\end{array}$ & $\mathbf{R}^{2}$ \\
\hline 55,0 & 56,7 & 16,62 & 0,92 & & \\
\hline 60,0 & 61,6 & 6,43 & 0,96 & 14,90 & 0,98 \\
\hline 65,0 & 66,3 & 3,78 & 0,96 & & \\
\hline
\end{tabular}


Coeficientes de determinação $\left(R^{2}\right)$ evidenciados nas curvas de destruição térmica variaram de aproximadamente 0,92 a 0,96 em ajustes do modelo matemático linear (tabela 1) indicando a ocorrência de mortalidade microbiana a taxas constantes. Valores de $R^{2}$ superiores a 0,90 , segundo Juneja e Marmer (1998), Novak et al. (2001), Novak e Yuan (2004), são aproveitados como parâmetro para seleção e caracterização da linearidade das curvas para estudo (análise de dados e expressão de resultados). Nossos resultados $\left(\mathrm{R}^{2}\right)$ apontam para caracterizações de curvas de destruição térmica isentas da influência da heterogeneidade de populações e adaptações térmicas durante o tratamento (PÁGAN et al., 1997; MURPHY et al., 1999; STRINGER et al., 2000). Isto se deve a não constatação de ombros e caudas nas curvas que, segundo Asselt e Zwietering (2006), reduzem a qualidade do ajuste do modelo matemático aos pontos experimentais anteparando, posteriormente, o emprego dos parâmetros de resistência obtidos na retificação de processos térmicos da indústria alimentar.

A constante de resistência térmica (valor Z) obtida considerando as temperaturas investigadas e apresentadas na tabela 1 foi de $14,9^{\circ} \mathrm{C}$ extraída de regressão com $\mathrm{R}^{2}$ de 0,98 . Este valor é diferente dos valores encontrados por outros autores que os obtiveram em variadas condições de estudo (e. g., Byrne et al., 2006 obtiveram um valor $Z$ de 7,7 , Wijnands et al., 2009 apresentaram valores que

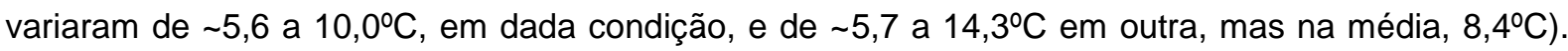
Asselt e Zwietering (2006) apresentaram valor médio de 10,3ㄷ procedente de outros cinco trabalhos (ROY et al., 1981; ICMSF, 1996; JUNEJA; MARMER, 1998; JUNEJA et al., 2001; NOVAK et al., 2001). Valor $Z$ é dependente de parâmetros obtidos nas curvas de destruição térmica estando, assim, também sob a influência dos mesmos fatores, estudados por outros autores, que sabidamente afetam as determinações destas referidas curvas. Fenômeno protetivo de células bacterianas atribuído a componentes alimentares de substratos (matrizes) experimentados são comumente encontrados e/ou mencionados por autores (e. g. JUNEJA; MARMER, 1998; JUNEJA et al., 2001; WIJNANDS et al., 2009) e possivelmente podem ter influenciado os padrões díspares aqui explicitados.

Outros valores $D$, relativos às temperaturas não investigadas neste trabalho, obtidos segundo modelo preditivo apresentado por Jackson (2015) são mostrados, parcialmente, na figura 1.

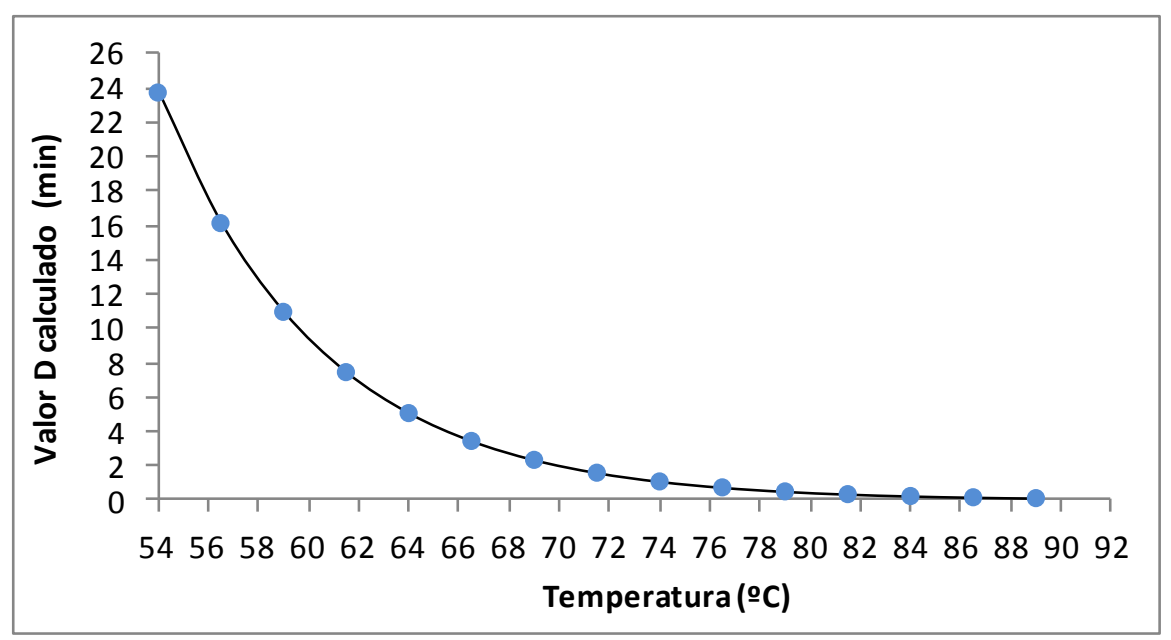


Figura 1 - Curva de tempos de redução decimal (valor D) de células vegetativas do Clostridium perfringens em patê de fígado com nozes e passas obtida com o modelo preditivo utilizado a partir de frações experimentais do primeiro grupo.

Para efetivação de uma redução decimal de $2 \log _{10}$ de células vegetativas de Clostridium perfringens no patê de fígado sob a temperatura de $67,5^{\circ} \mathrm{C}$, teoricamente, partindo do modelo

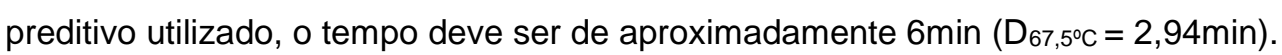

No experimento de menor letalidade térmica do segundo grupo de frações obteve-se $8,0 \times 10$ UFC/g de células sobreviventes após submeter amostra com população inicial enumerada de $6,0 \mathrm{x}$ $10^{3} \mathrm{UFC} / \mathrm{g}$ (controle) a condições de tratamento anteriormente mencionadas $\left(2 \mathrm{D}_{\left.67,5^{\circ} \mathrm{C}\right)}\right.$ necessárias para obtenção da redução pretendida (2 $\left.\log _{10}\right)$. Ao calcularmos o valor $D_{67,5^{\circ} \mathrm{C}}$ experimental (i. e., valor $D_{\text {observado }}$ de $3,14 \mathrm{~min}$ ), notou-se um valor muito aproximado ao valor $D_{\text {calculado }}$ obtido com o modelo preditivo (2,94min).

Experimentos do segundo grupo de frações que foram realizados considerando tratamentos com maior letalidade térmica $\left(8 \mathrm{D}_{67,5^{\circ} \mathrm{C}}\right.$ e $12 \mathrm{D}_{\left.67,5^{\circ} \mathrm{C}\right)}$ não apresentaram células sobreviventes, em ambos os casos, como já eram esperados.

A partir dos valores $D_{\text {observados }}$ e $D_{\text {calculados, }}$ considerando todas as temperaturas manipuladas no presente trabalho $\left(56,7,61,6,66,3\right.$ e $\left.67,5^{\circ} \mathrm{C}\right)$, obteve-se o coeficiente de correlação de Pearson ( $\mathrm{r}$ ). A relação entre os valores $D$, apresentada na figura 2, produziu correlação de 0,9934 evidenciando, para a faixa térmica investigada, marcada linearidade.

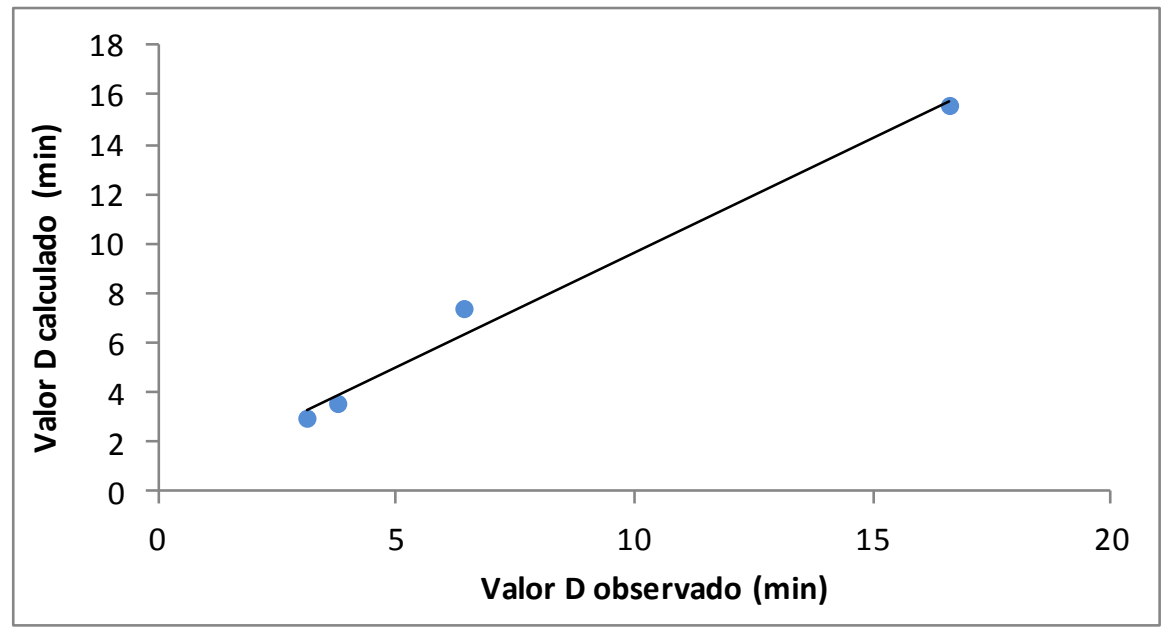

Figura 2 - Relação entre os tempos de redução decimal (observados e calculados) obtidos a partir de tratamentos térmicos de células vegetativas do Clostridium perfringens em patê de fígado com nozes e passas e do modelo preditivo utilizado.

Os quantitativos obtidos com a enumeração das células sobreviventes nos tratamentos de maior letalidade (i. e., $8 \mathrm{D}_{67,5^{\circ} \mathrm{C}}$ e $12 \mathrm{D}_{67,5^{\circ} \mathrm{C}}$ ), a semelhança dos valores $\mathrm{D}_{\text {observado }}$ e $\mathrm{D}_{\text {calculado }}(3,14 \mathrm{~min} \approx$ $2,94 \mathrm{~min}$ ) constatada no tratamento $2 \mathrm{D}_{67,5^{\circ} \mathrm{C}}$, resultado de elevada linearidade da relação examinada 
$(0,9934)$, corroboram para ratificar a eficiência do modelo preditivo utilizado no caso avaliado. Entretanto, faz-se necessário um número maior de dados concordantes com os padrões aqui evidenciados, tanto dentro do intervalo térmico estudado quanto o não estudado, para que se possa fazer uso da ferramenta, considerando o caso, dentro de padrões de segurança admitidos dos produtos alimentares envolvidos.

\section{Conclusão}

Os padrões aqui caracterizados colaboram para um melhor entendimento do controle bacteriano no âmbito da conservação de produtos cárneos (patê de fígado com nozes e passas) no que tange o emprego de processos térmicos adequados para destruição ou inativação de microrganismos.

$\mathrm{Da}$ investigação realizada depreende-se que a bactéria experimentada porta significativa resistência ao estresse térmico no substrato de patê de fígado com nozes e passas e que o modelo preditivo utilizado possui eficiência na obtenção dos tempos de tratamento térmico. No entanto, há que se considerarem demais fatores (e. g. oscilações de temperatura durante tratamento de frações experimentais, composição da matriz experimentada, aferição de equipamentos) que afetam a caracterização dos padrões aqui explicitados para um melhor aproveitamento das informações dentro do que se pretende.

\section{Agradecimentos}

À Fundação de Ciência e Tecnologia - CIENTEC, pela disponibilização de sua infraestrutura para a realização de ensaios pertinentes ao trabalho; ao produtor artesanal Newton Lauria; pela autorização para publicitar os resultados deste trabalho e pelo fornecimento das amostras de patês e aos colegas de laboratório, Elmo Lencina, Jorge Alfredo, Roque Sanabria e Vivian Estevan, pelo apoio técnico.

\section{Referências}

ASSELT, E.D.V; ZWIETERING, M.H. A systemic approach to determine global thermal inactivation parameters for various food pathogens. International Journal of Food Microbiology, v. 107, n. 1, p. 73-82. 2006.

BARRETTO, E.S.S. Doenças transmitidas por alimentos: Clostridium perfringens. In: Superintendência de controle de zoonoses, vigilância e fiscalização sanitária (SCZ). Boletim de divulgação técnica e científica, n. 5, Rio de Janeiro, 2000. Disponível em: <http://www6.ensp.fiocruz.br/visa/files/bol5.pdf>. Acessado em: 10 dez. 2017.

BYRNE, B. et al. Thermal inactivation of Bacillus cereus and Clostridium perfringens vegetative cells and spores in pork luncheon roll. Food Microbiology, n. 23, p. 803-808, 2006. 
FORSYTHE, S.J. Microbiologia da segurança dos alimentos. Porto Alegre: Artmed, 2002.

GOMES, A.M. et al. Genotipicação de Clostridium perfringens isolados de frangos de corte através da PCR múltipla. Ciência Rural, v. 38, n. 7, p. 1943-1947, 2008. Disponível em: <http://www.scielo.br/pdf/cr/v38n7/a22v38n7.pdf>. Acessado em: 25 nov. 2017.

GOTELLI, N.J.; ELLISON, A.M. Princípios de estatística em ecologia. Porto Alegre: Artmed, 2011.

HEREDIA, N.L. et al. Elevation of the heat resistance of vegetative cells and spores of Clostridium perfringens type A by sublethal heat shock. Journal of Food Protection, v. 60, n. 8, p. 998-1000, 1997.

HUANG, I-H. et al. Clostridium perfringens: sporulation, spore resistance and germination. Journal of Microbiology, Bangladesh, v. 24, n. 1, p. 1-8, 2007.

INTERNATIONAL COMMISSION ON MICROBIOLOGICAL SPECIFICATIONS FOR FOODS ICMSF. Microorganisms in Foods. London: Blackie Academic and Professional. 1996.

JACKSON, T.C. Thermoduric microorganisms and heat-resistance measurements. In: SALFINGER, Y.; TORTORELLO, M.L. (Eds.). Compendium of methods for the microbiological examination of foods. 5th ed. Washington: Americam Public Health Association, 2015. p. 191-200.

JAY, J.M. Microbiologia dos alimentos. 6.ed. Porto Alegre: Artmed, 2005.

JUNEJA, V.K. Thermal inactivation of microorganisms. In: JUNEJA, V.K.; SOFOS, J.N. (Eds.). Control of Foodborne Microorganisms. first ed. New York: Marcel Dekker, 2000. p. 13-52.

JUNEJA, V.K.; MARMER, B.S. Thermal inactivation of Clostridium perfringens vegetative cells in ground beef and turkey as affected by sodium pyrophosphate. Food Microbiology, n. 15, p. 281-287, 1998.

JUNEJA, V.K. et al. Heat resistance of Clostridium perfringens vegetative cells as affected by prior heat shock. Journal of Food Safety, v. 21, p. 127-139, 2001.

JUNEJA, V.K. et al. Predictive model for growth of Clostridium perfringens during cooling of cooked ground chicken. Innovative Food Science and Emerging Technologies, n. 10, p. 260-266, 2009.

JUNEJA, V.K. et al. Clostridium perfringens. In: JUNEJA, V.K.; SOFOS, J.N. (Eds.), Pathogens and Toxins in Foods: Challenges and Interventions. Washington: ASM Press, 2010. p. 53-70.

LABBE, R.G. Clostridium perfringens. In: SALFINGER, Y.; TORTORELLO, M.L. (Eds.). Compendium of methods for the microbiological examination of foods. 5th ed. Washington: Americam Public Health Association, 2015. p. 403-410.

LABBE, R.J.; JUNEJA, V.K. Clostridium perfringens. In: CLIVER, D.O.; RIEMANN, H. (Eds.). Foodborne Diseases. San Diego: Academic Press, 2002. p. 192-234.

MCCLANE, B.A. Clostridium perfringens. In: DOYLE, M.P.; BEUCHA, L.R. (Eds.). Food Microbiology: Fundamentals and Frontiers. Washington: ASM Press, 2007. p. 423-444.

MCMEEKIN, T.A. et al. Predictive microbiology: towards the interface and beyond. International Journal Food Microbiology, n. 73, p. 395-407, 2002.

MURPHY, R.Y. et al. Inactivation of Salmonella and Listeria in ground chicken breast meat during thermal processing. Journal of Food Protection, Fayertteville, v. 62, n. 9, p. 980-985, 1999. 
NOVAK, J.S; YUAN, J.T. Increased inactivation of ozone-treated Clostridium perfringens vegetative cells and spores on fabricated beef surfaces using mild heat. Journal of Food Protection, Chicago. v. 67, n. 2 , p. 342-346, 2004.

NOVAK, J.S. et al. Heat treatment adaptations in Clostridium perfringens vegetative cells. Journal of Food Protection, v. 64, n. 10, p. 1527-1534, 2001.

NOVAK, J.S. et al. Viability of Clostridium perfringens, Escherichia coli, and Listeria monocytogenes surviving mild heat or aqueous ozone treatment on beef followed by heat, alkali, or salt stress. Journal of Food Protection, v. 66, n. 3, p. 382-389, 2003.

OLSON, J.C.; NOTTINGHAM, P.M. Temperature. In: SILLIKER, J.H. Microbial ecology of food. New York: Academic Press. 1980, p. 1-37.

PAGÁN, R. et al. Effects of several factors on the heat-shock-induced thermotolerance of Listeria monocytogenes. Applied and Environmental Microbiology, v. 63, n. 8, p. 3225-3232, 1997.

RAJU, D.; SARKER, M.R. Comparison of the Levels of Heat Resistance of Wild-Type, cpe Knockout, and cpe Plasmid-Cured Clostridium perfringens Type A Strains. Applied and Environmental Microbiology, v. 71, n. 11, p. 7618-7620, 2005.

ROY, R.J. et al. Thermal inactivation of Clostridium perfringens after growth at several constant and linear rising temperatures. J. Food Science, v. 46, n. 5, p. 1586-1591, 1981.

SALFINGER, Y.; TORTORELLO, M.L. (Eds.). Compendium of methods for the microbiological examination of foods. 5th ed. Washington: Americam Public Health Association, 2015.

SARKER, M.R. et al. Comparative experiments to examine the effects of heating on vegetative cells and spores of Clostridium perfringens isolates carrying plasmid genes versus chromosomal enterotoxin genes. Applied Environmental Microbiology, v. 66, n. 8, p. 3234-3240, 2000.

SILVA, N. et al. Manual de Métodos de Análise Microbiológica de Alimentos e Água. 4 ed. São Paulo: Livraria Varela, 2010.

SINELL, H. J. Interacting factors affecting mixed populations. In: SILLIKER, J.H. Microbial ecology of food. New York: Academic Press, 1980. p. 215-231.

STRINGER, S.C. et al. Thermal inactivation of Escherichia coli 0157:H7. Journal of Applied Microbiology Symposium Supplement, n. 88, p. 798-898, 2000.

WIJNANDS, L.M. et al. Heat sensitivity of Clostridium perfringens. Rijksinstituut voor Volksgezondheid en Milieu. Bilthoven, 2009. Disponível em: <http://www.rivm.nl/dsresource?objectid=befe1a48-4c79-4b8f-aa11-

4af34f4fab83\&type=org\&disposition=inline >. Acessado em: 15 dez. 2017. 